\title{
An Updated Review on Some Neurotoxicpharmacological Agents Along with their Neurotoxic Mechanisms
}

\author{
Muhammad Irfan Bashir'1, Nur Hidayah Kaz Abdul Aziz' ${ }^{1}$ Dzul Azri Mohamed Noor² \\ ${ }^{1}$ Researcher, Discipline of Pharmacology, School of Pharmaceutical Sciences, Universiti Sains Malaysia, Minden \\ 11800, Penang, Malaysia, ${ }^{2}$ Discipline of Clinical Pharmacy, School of Pharmaceutical Sciences, Universiti Sains \\ Malaysia, Minden 11800, Penang, Malaysia
}

\begin{abstract}
This review will provide the vital information about some pharmacological agents which are Neurotoxic. Through this update, Anti-cancer, Anti-bacterial, Analgesic, Psychoactive drug and Anabolic steroid medication are reported briefly regarding their neurotoxic mechanisms. In this review all information regarding neurotoxic drugsis collected from 2020 published work by Web of science, Scopus, PubMed and Google Scholar. It is concluded that all these drugs which the part of our study areneurotoxic. There is need to discover some methodto reduce their toxicity and to avoid the chronic use of these medications.
\end{abstract}

Keywords: Neurotoxic, Pharmacological agents, Anti-cancer, Analgesic, Antibacterial.

\section{Introduction}

Several types of drugs have side effects on brain, some are minimal, and some are toxic. Toxic effects of drug on brain can cause irreversible brain damage sometimes which are very dangerous for mental health, as any living organism can lose its life due severe neurotoxicity ${ }^{1}$. In routine treatments we don't know about some drugs which we are taking has negative impact on our mental health as well as on our nervous system $^{2}$.

Neurotoxicity is a major side effect of many chemotherapeutic drugs used for the treatment of many diseases, including tumors.Toxicitycan compromise the quality of life of patients. As per previous reports $84.4 \%$ of patients which were affected by lymphoma and treated with chemotherapeutic agents developed a serious neuropathy regarding sensory organs and

\section{Corresponding Author:}

Muhammad Irfan Bashir

Discipline of Pharmacology, School of Pharmaceutical

Sciences, Universiti Sains Malaysia, Minden 11800,

Penang, Malaysia

e-mail: mirfanbashir786@gmail.com
$43.8 \%$ showed polyneuropathy, causing a significantly dangerous for the quality of life ${ }^{3}$.

Such effects are usually cause spontaneously fade, asdoses are high then chances of neurotoxicity are also high $^{4}$. If these drugs are used at high therapeutic levels for longtime, the plasticity of the neurons is affected badly, and the damage becomes irreversible sometimes ${ }^{5}$.

Neurotoxicity is one of the main reasons of drug withdrawal, and the biological experimental method of evaluating neurotoxicity are time taking and arduous. Many Anti-biotic, Analgesic are also showed their neurotoxicity due to their cytotoxic and neurochemical disturbing mechanisms ${ }^{6}$.

In this updated review, adverse effects of some drugs that cause neurotoxicity are explained individually. These updates are collected from recently published work in 2020. Among these drugs, anti-cancer, antibacterial, Analgesic, Psychoactive drug and Anabolic steroid medication are reported briefly. Table 1 is showing summarized report regarding some neurotoxic drugs with their mechanism. 
Table 1: Neurotoxic Drugs with mechanisms

\begin{tabular}{|c|c|c|c|}
\hline Drug & Class & Neurotoxic Mechanism & $\begin{array}{l}\text { Year of } \\
\text { Publish }\end{array}$ \\
\hline Bortezomib & Anti-cancer & $\begin{array}{l}\text { Apoptosis in PC12 is a cell line derived from a pheochromocytoma of the } \\
\text { rat adrenal medulla, that have an embryonic origin from the neural crest } \\
\text { that has a mixture of neuroplastic cells and eosinophilic cells. }\end{array}$ & 2020 \\
\hline Doxorubicin & Anti-cancer & $\begin{array}{l}\text { It Interact with nuclear DNA and impairing expression of proteins } \\
\text { synthesis, involved in mitochondrial functions }\end{array}$ & 2020 \\
\hline Cisplatin & Anti-cancer & $\begin{array}{l}\text { It also interreacts with DNA, forms crosslinks in between chains and } \\
\text { induces apoptosis. It can cause Central and Peripheral neuropathy }\end{array}$ & 2020 \\
\hline Carboplatin & Anti-cancer & $\begin{array}{l}\text { Inhibition of the DNA repair pathways, generation of DNA adducts in } \\
\text { brain cells }\end{array}$ & 2020 \\
\hline Oxaliplatin & Anti-cancer & $\begin{array}{l}\text { Alterations in voltage-gated sodium channel kinetics,Potassium channel } \\
\text { blockade, Calcium chelation and sensory axonal nerve damage }\end{array}$ & 2020 \\
\hline Ifosfamide & Anti-cancer & Ifosfamideinhibits the DNA functions and induces cell death. & 2020 \\
\hline 5-Fluorouracil & Anti-cancer & $\begin{array}{l}\text { Interferences with DNA synthesis; inhibits of thymidylate synthase; } \\
\text { blocks of thymidine formation }\end{array}$ & 2020 \\
\hline $\begin{array}{l}\text { Novel } \\
\text { Methcathinones }\end{array}$ & Psychoactive drug & $\begin{array}{l}\text { Mitochondrial toxicants whose toxicity is increased by shifting the } \\
\text { temperature from } 37 \text { to } 40.5^{\circ} \mathrm{C} \text { (Hyperthermia) }\end{array}$ & 2020 \\
\hline Methotrexate & Anti-cancer & $\begin{array}{l}\text { Inhibition of the enzyme dihydrofolate reductase; interference with DNA } \\
\text { synthesis, DNA repair, cellular replication, protein synthesis, lipids and } \\
\text { myelin metabolism. motor and autonomic neuropathy) }\end{array}$ & 2020 \\
\hline Cefepime & Anti-Bacterial & $\begin{array}{l}\text { Cross the blood brain barrier and cause depressed concentration of } \\
\text { consciousness, confusion, aphasia, asterixis, myoclonus, dystonia, seizure } \\
\text { in } 23.2 \% \text { population. }\end{array}$ & 2020 \\
\hline $\begin{array}{l}\text { Nandrolone } \\
\text { decanoate }\end{array}$ & $\begin{array}{l}\text { Anabolic steroid } \\
\text { medication }\end{array}$ & $\begin{array}{l}\text { Oxidative stress, inflammation, and intrinsic and extrinsic apoptosis in the } \\
\text { hippocampus and PFC of rats }\end{array}$ & 2020 \\
\hline Cannabis & Psychoactive drug & Apoptosis in the hippocampus and PFC of rats & 2020 \\
\hline Tramadol & Analgesics & $\begin{array}{l}\text { It can trigger the microgliosis and astrogliosis along with neuronal death } \\
\text { in the prefrontal cortex }\end{array}$ & 2020 \\
\hline $\begin{array}{l}\text { N-Ethylhexedrone } \\
\text { and buphedrone }\end{array}$ & $\begin{array}{l}\text { Novel Psychoactive } \\
\text { Substances }\end{array}$ & Neuro-microglia dysfunctionalities & 2020 \\
\hline
\end{tabular}

Bortezomib: Bortezomib is an anti-tumor agent that inhibits $26 \mathrm{~S}$ proteasome degrading proteins. While apoptotic transcription activation in response to bortezomib has also been observed, mechanisms regarding influence on gene silencing mediated regulation by non-coding RNAs remain not fully explained ${ }^{7}$. Bortezomib showed the severe neurotoxicity through apoptosis in PC12 cells. It imparts neurotoxicity regardless of cell density ${ }^{8}$. Some studies also showed that, highest cytotoxicity in low cell density, bortezomib more frequently cause major peripheral neuropathy, only few of studies have reported the effective strategy to prevent its side effect ${ }^{9}$.

Doxorubicin: Doxorubicin is the most potent anthracycline antibiotics used for treatment of multiple cancer types including breast cancer therapy. But its efficacy is limited by fatal toxicities associated with therapy causing damage to normal tissues and organs ${ }^{10}$. It Interacts with nuclear DNA, altering the pair base sequence and preventing the topoisomerase-II-mediated DNA repair mitochondrial DNA, impairing expression of proteins involved in mitochondrial functions ${ }^{3,11}$.

Cisplatin: Cisplatin is an anti-cancer drug it interreacts with DNA, forms crosslinks between chains and induces apoptosis. Central or Peripheral neuropathy. $50-85 \%$ score of sensory and sensorimotor neuropathy. Oxidative stress, generation of DNA adducts, apoptosis, mitochondrial dysfunctionare also among its neurotoxic mechanisms ${ }^{12}$. Cisplatin also react with RNA but the ration of modified molecules to the total number of the 
same molecular species in the cell is much higher in the case of DNA molecules, binding of this agent to the DNA is the main cause of its toxicity ${ }^{13}$.

Carboplatin: Carboplatin is widely used agent to treat the various types of cancer. However, anumber of severe side effects induced by the nonspecific binding of platinum drugs tonormal tissues limit their clinical use ${ }^{14}$. This drug is also involved in Inhibition of the DNA repair pathways, generation of DNA adducts and cause severe neurotoxicity ${ }^{3,15}$.

Oxaliplatin: Oxaliplatin is involved in acute neuropathy upon exposure to chronic peripheral neuropathy, in which sensory axonal nerve abnormalgeneration of DNA adducts is occurred. Mostly due to Alterations in voltage-gatedsodium channel kinetics, Calcium chelation and Potassium channel blockade $^{3}$. Peripheral neurotoxicity is a main toxicity that afflicts up to $90 \%$ of patients with colorectal cancer which are taking oxaliplatincontaining therapy ${ }^{16,17}$.

Ifosfamide: Ifosfamide is an alkylating agent used in the treatment of various solid tumors, including small cell lung cancer, testicular cancer, cervical cancer, andsarcoma ${ }^{18}$. It is Pro-drug, that after bioactivation, inhibits the DNA functions and cause cell death ${ }^{3}$. Chloroacetaldehyde (metabolite responsible for neurotoxicity) inducing many damages to the mitochondrial respiratory chain depletion of glutathione level in central nervous system and also creating oxidative stress ${ }^{19}$.

5-Fluorouracil: This drug also reacts with DNA synthesis and inhibits of thymidylate synthase which blocks the thymidine formation. Seldomly sensorimotor polyneuropathy is observed during treatment with 5-Flurouracil ${ }^{20}$. Maximum doses and combined use of 5-FU with interferon alpha increases the neurotoxicity. Itimpairs the urea cycle and permits an accumulation of ammonia a transient stagnation of 5-FU catabolites induces neurotoxicity. This drug can increase the cellular thiamine metabolism, inducing a thiamine deficiency ${ }^{3,21}$.

Novel Methcathinones: These are mitochondrial toxicants whose toxicity is increased by transferring the temperature from 37 to $40.5^{\circ} \mathrm{C}$. It can cause apoptosis and necrosis among brain cells ${ }^{22}$. The activation of proper defense mechanisms like autophagy is necessary to prevent the cell dysfunction and cell death. Mitochondrial toxicity, which is accentuated by hyperthermia, represents an important mechanism of the neural toxicity of these compounds ${ }^{23}$.

Methotrexate: Methotrexate is a folic acid antagonist for the treatment ofcancer and rheumatoid arthritis because of its high potency and efficacy ${ }^{24}$. It inhibits the enzyme dihydrofolate reductase which interference with DNA synthesis, DNA repair, protein synthesis, cellular replication, lipids and cause autonomic neuropathy ${ }^{25}$. Aseptic meningitis occurs in $10-50 \%$ of patients due to influence of this drug. Disturbances of myelin metabolism, inhibition of glucose metabolism, oxidative stress ${ }^{3,26}$.

Cefepime: Cefepime is an antibacterial drug belongs to cephalosporins, previously its concentrations were determined in 584 individuals. Among 319 individuals with available through concentrations included, the overall incidence of neurotoxicity was $23.2 \%$ (74 of 319 individuals). Maximum cefepime plasma trough concentrations were significantly associated with risk of neurotoxicity ${ }^{27}$. Possible adverse neurological effects based on the occurrence of neurological signs (altered mental status, depressed concentration of consciousness, aphasia, myoclonus, asterixis, confusion, seizure, dystonia ${ }^{28}$.

Nandrolone decanoate with Cannabis: These are Psychoactive drugs. Polydrug use among adolescence is a widespread activity and has enhanced in the last some years $^{29}$. Most nandrolone decanoate abusers combine its use with cannabis. Abuse of both drugs conferred larger neurotoxic effects than either drug alone that were at least partially attributed to inflammation, oxidative stress, and apoptosis in the hippocampus and prefrontal cortex of brain in rats ${ }^{30}$.

Tramadol: Tramadol is a synthetic analogue of codeine that is prescribed for the treatment of moderate pains as an analgesic ${ }^{31}$. It has alsosome side effects including emotional instability and anxiety. it triggersastrogliosisand microgliosis along with neuronal death in the prefrontal cortex ${ }^{32}$. Behavioral problems and cognitive function impairment are other side effects of tramadol. Previous results indicate that tramadol is responsible for neurodegeneration in the prefrontal cortex through activation of neuroinflammatory response $\mathrm{s}^{33}$.

Cathinones N-Ethylhexedrone and buphedrone: $\mathrm{N}$-Ethylhexedrone and buphedrone are emerging synthetic cathinones ${ }^{34}$.Small information about their negative effects within central nervous system. These drugs showed in vivo/in vitro neurotoxicity's but 
enhanced specific N-Ethylhexedrone induced behavioral and neuro-microglia abnormalities ${ }^{35}$.

\section{Conclusion}

Due to reported neurotoxic mechanisms of all discussed drugs in this review, it is concluded that long term use of these medication can cause brain damaged. There is need to find some method to overcome the neurotoxic effects of all these drugs.

Source of Support: We acknowledge USM (Universiti Sains Malaysia) fellowship scheme support for Muhammad Irfan Bashir.

Conflict of Interest: No any conflict of interest

Ethical Declaration: This is a review article so there is no need to get its ethical approval.

\section{References}

1. Chhibber T, Bagchi S, Lahooti B, Verma A, AlAhmad A, Paul MK, et al. CNS organoids: an innovative tool for neurological disease modeling and drug neurotoxicity screening. Drug Discovery Today. 2020;25(2):456-65.

2. Hassan M, Awadalla E, Ali R, Fouad S, AbdelKahaar E. Thiamine deficiency and oxidative stress induced by prolonged metronidazole therapy can explain its side effects of neurotoxicity and infertility in experimental animals: Effect of grapefruit co-therapy. Human \& Experimental Toxicology. 2020;39(6):834-47.

3. Pellacani C, Eleftheriou G. Neurotoxicity of antineoplastic drugs: Mechanisms, susceptibility, and neuroprotective strategies. Advances in Medical Sciences. 2020;65(2):265-85.

4. Li F, Song L, Yang X, Huang Z, Mou X, Syed $A$, et al. Anticancer and genotoxicity effect of (Clausena lansium (Lour.) Skeels) Peel ZnONPs on neuroblastoma (SH-SY5Y) cells through the modulation of autophagy mechanism. Journal of Photochemistry and Photobiology B: Biology. 2020;203:111748.

5. Straehla JP, Warren KE. Pharmacokinetic Principles and Their Application to Central Nervous System Tumors. Pharmaceutics. 2020;12(10):948.

6. Dietrich J. Neurotoxicity of Cancer Therapies. CONTINUUM: Lifelong Learning in Neurology. 2020;26(6):1646-72.
7. Łuczkowska K, Rogińska D, Ulańczyk Z, Paczkowska E, Schmidt CA, Machaliński B. Molecular mechanisms of bortezomib action: novel evidence for the miRNA-mRNA interaction involvement. International Journal of Molecular Sciences. 2020;21(1):350.

8. Iijima Y, Bandow K, Amano S, Sano M, Hino S, Kaneko T, et al. Protection of bortezomib-induced neurotoxicity by antioxidants. Anticancer Research. 2020;40(7):3685-96.

9. Stage TB, Hu S, Sparreboom A, Kroetz DL. Role for Drug Transporters in Chemotherapy-Induced Peripheral Neuropathy. Clinical and Translational Science. 2020.

10. Alvi MM. Lysosomal targeting of a gelatindoxorubicin conjugate and its evaluation for cell damage in two model breast cancer cell lines: University of the Sciences in Philadelphia; 2020.

11. Gao Y, Shang Q, Li W, Guo W, Stojadinovic A, Mannion C, et al. Antibiotics for cancer treatment: A double-edged sword. Journal of Cancer. 2020;11(17):5135.

12. dos Santos NAG, Ferreira RS, dos Santos AC. Overview of cisplatin-induced neurotoxicity and ototoxicity, and the protective agents. Food and chemical toxicology. 2020;136:111079.

13. Niaki EF, Van Acker $T$, Imre L, Nánási $P$, Tarapcsák S, Bacsó Z, et al. interactions of cisplatin and Daunorubicin at the chromatin Level. Scientific reports. 2020;10(1):1-12.

14. Yao H, Chen S, Deng Z, Tse M-K, Matsuda Y, Zhu G. BODI-Pt, a Green-Light-Activatable and Carboplatin-Based Platinum (IV) Anticancer Prodrug with Enhanced Activation and Cytotoxicity. Inorganic Chemistry. 2020;59(16):11823-33.

15. Stankovic JSK, Selakovic D, Mihailovic V, Rosic G. Antioxidant Supplementation in the Treatment of Neurotoxicity Induced by Platinum-Based Chemotherapeutics-A Review. International Journal of Molecular Sciences. 2020;21(20):7753.

16. Huang KM, Leblanc AF, Uddin ME, Kim JY, Chen M, Eisenmann ED, et al. Neuronal uptake transporters contribute to oxaliplatin neurotoxicity in mice. The Journal of Clinical Investigation. 2020.

17. Alberti P, Canta A, Chiorazzi A, Fumagalli G, Meregalli C, Monza L, et al. Topiramate prevents oxaliplatin-related axonal hyperexcitability and 
oxaliplatin induced peripheral neurotoxicity. Neuropharmacology. 2020;164:107905.

18. Yeager J, Basnet A. Delayed Ifosfamide Neurotoxicity. American Journal of Therapeutics. 2020;27(6):e613-e4.

19. Çelik H, Kucukler S, Çomaklı S, Özdemir S, Caglayan C, Yardım A, et al. Morin attenuates ifosfamide-induced neurotoxicity in rats via suppression of oxidative stress, neuroinflammation and neuronal apoptosis. Neurotoxicology. 2020;76:126-37.

20. Ray J, Mahmood A, Dogar M, Guo J, Nwamaghinna F, Salciccioli L, et al. Simultaneous Cardiotoxicity and Neurotoxicity Associated with 5-fluorouracil Containing Chemotherapy: A Case Report and Literature Review. American journal of medical case reports. 2020;8(3):73.

21. Boilève A, Thomas L, Lillo-Le Louët A, Gaboriau L, Chouchana L, Ducreux M, et al. 5-Fluorouracilinduced hyperammonaemic encephalopathy: A French national survey. European Journal of Cancer. 2020;129:32-40.

22. Zhou X, Bouitbir J, Liechti ME, Krähenbühl S, Mancuso RV.Hyperthermia Increases Neurotoxicity Associated with Novel Methcathinones. Cells. 2020;9(4):965.

23. Mancuso RV.HyperthermiaIncreases Neurotoxicity Associated with Novel Methcathinones.

24. Hannoodee M, Mittal M. Methotrexate. StatPearls [Internet]. 2020.

25. RiazA, GhaffarM,SalahuddinH.Pharmacogenomics of Methotrexate-Induced Toxicity in Children. 'Essentials of Cancer Genomic, Computational Approaches and Precision Medicine: Springer; 2020. p. 401-12.

26. Yust-Katz S, Khagi S, Gilbert MR. Neurologic complications. Abeloff's Clinical Oncology: Elsevier; 2020. p. 688-706. e7.

27. Boschung-Pasquier L, Atkinson A, Kastner LK, Banholzer S, Haschke M, Buetti N, et al. Cefepime
Medico-legal Update, April-June 2021, Vol. 21, No. 2

neurotoxicity: thresholds and risk factors. A retrospective cohort study. Clinical microbiology and infection. 2020; 26(3):333-9.

28. Ojha N, Riaz S, Eranki A. Cefepime Neurotoxicity in a Patient With Acute Tubular Necrosis. Cureus. 2020;12(8).

29. Pavlek LR, Dillard J, Rogers LK. The Role of Oxidative Stress in Toxicities due to Drugs of Abuse. Current Opinion in Toxicology. 2020.

30. El-Shamarka ME-S, Sayed RH, Assaf N, Zeidan HM, Hashish AF. Combined neurotoxic effects of cannabis and nandrolone decanoate in adolescent male rats. Neurotoxicology. 2020;76:114-25.

31. Motahare K. Evaluation of the molecular mechanism of neurotoxicity, reproductive toxicity and dependency of tramadol via assessment of behavioral test and NF-KB, inflammation and apoptosis pathways in male rats: protective effect of 1-carnitine and melatonin: Mazandaran university of medical sciences; 2020.

32. Aghajanpour F, Boroujeni ME, Jahanian A, Soltani R, Ezi S, Khatmi A, et al. Tramadol: a Potential Neurotoxic Agent Affecting Prefrontal Cortices in Adult Male Rats and PC-12 Cell Line. Neurotoxicity research. 2020.

33. Ali HA, Afifi M, Saber TM, Makki AA, Keshta A, Baeshen M, et al. Neurotoxic, Hepatotoxic and Nephrotoxic Effects of Tramadol Administration in Rats. Journal of Molecular Neuroscience. 2020:1-9.

34. Carrola J, Duarte N, Florindo P, Henriques S, da Silva G, Bijlsma L, et al. Metabolism of $\mathrm{N}$-ethylhexedrone and buphedrone: $\mathrm{An}$ in vivo study in mice using HPLC-MS/MS. Journal of Chromatography B. 2020;1159:122340.

35. de Mello-Sampayo C, Vaz AR, Henriques SC, Fernandes A, Paradinha F, Florindo P, et al. Designer Cathinones N-Ethylhexedrone and Buphedrone Show Different In Vitro Neurotoxicity and Mice Behaviour Impairment. Neurotoxicity Research. 2020:1-21. 